\title{
Effects of Exercise Training on Left Ventricular Function Evaluated by the Tei Index in Patients With Myocardial Infarction
}

\author{
Kenji Ueshima, MD; Takashi Suzuki, MD; Masataka Nasu, MD; Masahiko Saitoh, MD; \\ Noboru Kobayashi, MD; Takuya Yamazaki, MD; Katsuhiko Hiramori, MD
}

\begin{abstract}
Background This study investigated the influence of exercise training on left ventricular (LV) function in patients with acute myocardial infarction (AMI) using a new index of cardiac function, the Tei index.

Methods and Results The study enrolled 53 consecutive patients (36 males, 17 females; mean age: $65 \pm 10$ years) with AMI. Exercise training was performed for 6 months; peak $\mathrm{V}_{2}$ and the Tei index were measured at the start of the cardiac rehabilitation program and 1,3, and 6 months later. The peak $\mathrm{V}_{2}$ improved from $14.3 \pm$ 3.3 to $18.5 \pm 5.2 \mathrm{ml} \cdot \mathrm{min}^{-1} \cdot \mathrm{kg}^{-1}$ after 6 months $(\mathrm{p}<0.01)$. Although there were no significant changes in LV ejection fraction over the 6 months, the Tei index improved from $0.50 \pm 0.18$ to $0.41 \pm 0.19(\mathrm{p}<0.05)$. When the $\Delta$ Tei index was compared among the 3 groups classified by the Tei index at baseline, the values improved in the groups with high/slightly high values compared with the normal group.

Conclusion Both cardiac function, as evaluated by the Tei index, and exercise capacity improved after exercise training in patients with AMI. The greater improvement was seen in the population with the higher value (lower cardiac function) according to this index. (Circ J 2005; 69: 564-566)
\end{abstract}

Key Words: Acute myocardial infarction; Exercise training; Left ventricular function; Tei index

$\mathbf{S}$ everal studies have reported the influence of exercise training on left ventricular (LV) contractility in patients with myocardial infarction (MI), although consensus has not been obtained; no changes in resting contractility were observed,-4 improvement was achieved only in patients with cardiac dysfunction, deterioration was observed only in patients with cardiac dysfunction, ${ }^{6} \mathrm{LV}$ ejection fraction (LVEF) during exercise improved?, 8

The present study was conducted to investigate the influence of exercise training on LV function and exercise tolerance in patients with acute MI (AMI) using a new index of cardiac function, the Tei index. The Tei index is an echocardiographic/Doppler index of the combined LV systolic and diastolic function. We investigated the correlation between the Tei index, LVEF as a marker for systolic function, and exercise capacity in patients with AMI who were enrolled in a cardiac rehabilitation program.

\section{Methods}

The study population comprised 53 consecutive patients (36 males, 17 females; mean age: $65 \pm 10$ years) admitted to hospital for AMI. Patients were excluded if they had some risks associated with exercise training, such as coronary artery disease with residual myocardial ischemia and severe aortic stenosis, if they had orthopedic or neuromuscular or if they had frequent ectopic beats or atrial fibrillation. An

(Received October 29, 2004; revised manuscript received January 11, 2005; accepted February 2, 2005)

Memorial Heart Center, The Second Division of Internal Medicine, Iwate Medical University, Morioka, Japan

Mailing address: Kenji Ueshima, MD, Second Department of Internal Medicine, 19-1 Uchimaru, Morioka, Iwate 020-8505, Japan. E-mail:

k_ueshima@imu.ncvc.go.jp anterior wall infarction developed in $45 \%$ of the patients, $6 \%$ of the patients had a history of old MI and $60 \%$ of the patients underwent reperfusion therapy in the acute stage. Mean LVEF in the acute stage was $52 \%$. According to the Killip's classification, 94\% of the patients were I or II.

The in-hospital and outpatient cardiac rehabilitation program for patients with AMI was either a 2- or 3-week program according to the Guideline for Rehabilitation of Cardiovascular Patients and was supported by a research grant for cardiovascular diseases (5C-3) from the Ministry of Health and Welfare from 1993 until 1995 (Director Muneyasu Saito). Exercise training, which was prescribed on the basis of $90 \%$ intensity of the anaerobic threshold, was performed 2-3 times per week for 6 months. Acutestage exercise training during admission was performed under monitoring and chronic-stage exercise therapy was continued under monitoring at the outpatient clinic or unsupervised at home. In principle, subjects maintained their medications throughout the study. Prior to participation, informed consent was obtained from each patient.

Cardiopulmonary exercise testing (CPX) and 2-dimensional Doppler echocardiography (2D-Echo) were carried out at the start of the cardiac rehabilitation program and at 1,3 , and 6 months later. Peak $\dot{\mathrm{V}}_{2}$ was measured during CPX as described previously ${ }^{9}$ and the LVEF and Tei index were obtained by 2D-Echo! ${ }^{10}$ The measurement of LVEF used a modified Simpson's method with the apical 4-chamber view and the Tei index (normal range: $0.39 \pm 0.05$ ), defined as the sum of the isovolumetric contraction time and isovolumetric relaxation time divided by ejection time, was measured from the LV outflow and mitral inflow Doppler velocity profiles as described by Tei et al $!^{0}$

In addition, the subjects were divided into 3 groups according to their Tei index before the start of exercise train- 

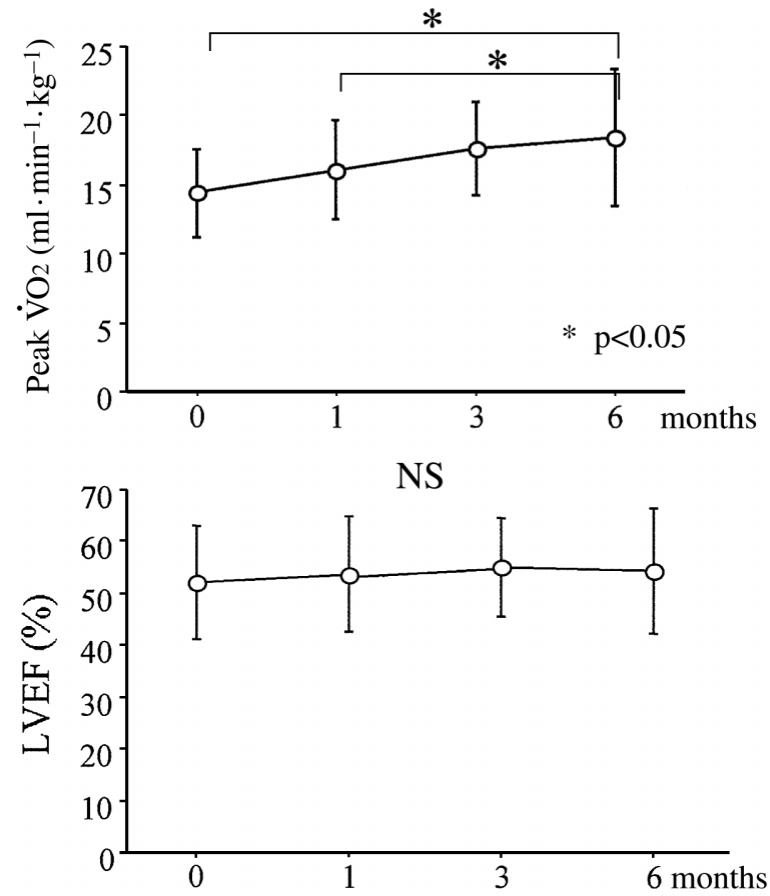

Fig 1. Changes in peak $\dot{\mathrm{V}}_{2}$ during exercise training (Upper panel). Changes in left ventricular ejection fraction (LVEF) during exercise training (Lower panel). The peak $\dot{\mathrm{V}}_{2}$ improved from $14.3 \pm 3.3$ at the start of the cardiac rehabilitation program to $18.5 \pm 5.2 \mathrm{ml} \cdot \mathrm{min}^{-1} \cdot \mathrm{kg}^{-1}$ $(\mathrm{p}<0.01)$ after 6 months, although there were no significant changes in resting LVEF over that period.

ing: the normal group $<0.4$; the group with a slightly high value $(0.4 \leq<0.6)$; and the group with a high value $\geq 0.6$.

For statistical analysis, ANOVA was used and $\mathrm{p}<0.05$ was regarded as significant. The data are expressed as the mean \pm standard deviation.

\section{Results}

The peak $\dot{\mathrm{V}} \mathrm{O}_{2}$ improved from $14.3 \pm 3.3 \mathrm{ml} \cdot \mathrm{min}^{-1} \cdot \mathrm{kg}^{-1}$ at the start of cardiac rehabilitation program to $18.5 \pm 5.2 \mathrm{ml}$. $\mathrm{min}^{-1} \cdot \mathrm{kg}^{-1}(\mathrm{p}<0.01)$ after 6 months (Fig 1, Upper panel). Although there were no significant changes in the resting LVEF over the 6 months (Fig 1, Lower panel), the Tei index improved from $0.50 \pm 0.18$ to $0.41 \pm 0.19(\mathrm{p}<0.05)$ (Fig 2, Upper panel).

In addition, the $\Delta$ Tei index was calculated from the difference between the baseline value and the value after 6 months of exercise training. When the $\Delta$ Tei index was compared among the 3 groups, the value had improved in the groups with high or slightly high values (lower cardiac function) compared with the normal group $(-0.22 \pm 0.16$, $-0.13 \pm 0.14,+0.02 \pm 1.0, \mathrm{p}<0.05)($ Fig 2 , Lower panel $)$.

\section{Discussion}

Exercise training is recommended for patients after AMI because of its beneficial effects, even though the reported effects of exercise training on cardiac function in these patients are still contradictory. Ornish et al found that patients in the exercise group demonstrated improved LVEF during peak exercise? but Jugdutt et al reported that patients with lower LVEF developed further functional and topographic
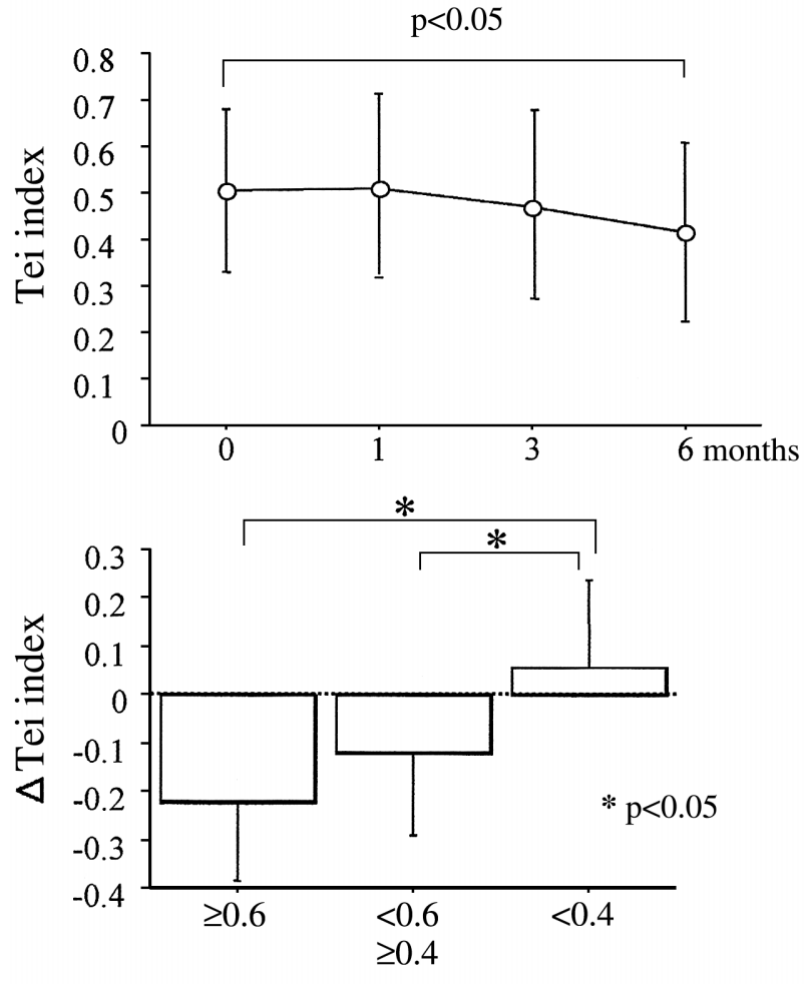

The Tei index before Exercise Training

Fig 2. Changes in the Tei index during exercise training (Upper panel) and in each group classified according to the baseline value of the Tei index (Lower panel). The Tei index improved from $0.50 \pm 0.18$ to $0.41 \pm 0.19(\mathrm{p}<0.05)$ and when the $\Delta$ Tei index was compared among the 3 groups, the value improved in the groups with high or slightly high baseline values (lower cardiac function) compared with the normal group $(-0.22 \pm 0.16,-0.13 \pm 0.14,+0.02 \pm 1.0, \mathrm{p}<0.05)$.

deterioration with exercise training. Giannuzzi et $\mathrm{al}^{5}$ reported that in the in EAMI trial post infarction patients without clinical complications, even those with a large infarction, had a possible benefit from long-term physical training without any additional negative effect on ventricular size or topography. Recently, Otsuka et al reported that patients with moderate to severe LV dysfunction benefited from exercise training started early after AMI without any deterioration in LV remodeling, with a similar magnitude of improvement in exercise capacity to that in patients with mild LV dysfunction.1 ${ }^{1}$ Because Eto et al ${ }^{12}$ reported that aerobic exercise training started early after the onset of AMI significantly increased cardiac output during exercise, we believe this difference of opinion is partly derived from limitations of the methods to evaluate cardiac function.

LVEF is most commonly used as an index of contractility. In the present study, although the effects of exercise training were not reflected in changes in LVEF, they were detected when using the Tei index. The Tei index, (isovolu metric contraction time + isovolumetric relaxation time)/ ejection time, is a new, simple, and reproducible index of combined systolic and diastolic myocardial performance. It has several practical and conceptual advantages: (1) it is easily obtained from conventional Doppler recordings; ${ }^{10}$ (2) it has a wide range of values that correlate with a wide range of severity; ${ }^{13}$ (3) there is no need to normalize heart rate or blood pressure; 13 (4) it is not dependent on ventricular geometry; (5) it is applicable to left ${ }^{13,14}$ and right ${ }^{15}$ heart 
function; and (6) it pertains to both systolic and diastolic performance 16 The Tei index has been found to be a strong predictor of mortality in patients with dilated cardiomyopathy 13

In the present study, there were no observable changes in LVEF as an index of systolic function and although improved diastolic function by physical training has been reported, ${ }^{17-19}$ we could not clarify an improvement indeceleration time as an index of diastolic function. We also could not clarify why the Tei index improved. However, because the Tei index and the exercise tolerance improved regardless of the severity of cardiac dysfunction evaluated by the Tei index at baseline, patients with a variety of cardiac dysfunctions detected using the Tei index can undergo exercise training.

\section{Study Limitations}

This study was not a randomized controlled trial, but despite being an observational study we were able to show the effect of exercise training on LV function using the Tei index and exercise tolerance.

\section{Conclusion}

Both cardiac function, which was evaluated by the Tei index, and exercise capacity improved after exercise training in patients with AMI and the greater improvement was seen in those with a higher baseline value (lower cardiac function) for the index.

\section{References}

1. Hung J, Gordon EP, Houston N, Haskell WL, Goris ML, DeBusk RF. Changes in rest and exercise myocardial perfusion and left ventricular function 3 to 26 weeks after clinically uncomplicated acute myocardial infarction: Effects of exercise training. Am J Cardiol 1984; 54: 943-950.

2. Nolewajka AJ, Kostuk WJ, Rechnitzer PA, Cunningham DA. Exercise and human collateralization: An angiographic and scintigraphic assessment. Circulation 1979; 60: 114-121.

3. Froelicher V, Jensen D, Genter F, Sullivan M, McKirnan MD, Witztum K, et al. A randomized trial of exercise training in patients with coronary heart disease. JAMA 1984; 252: 1291-1297.

4. Hertzeanu HL, Shemesh J, Aron LA, Aron AL, Peleg E, Rosenthal $\mathrm{T}$, et al. Ventricular arrhythmias in rehabilitated and nonrehabilitated post-myocardial infarction patients with left ventricular dysfunction. Am J Cardiol 1993; 71: 24-27.

5. Giannuzzi P, Tavazzi L, Temporelli PL, Corra U, Imparato A, Gattone $\mathrm{M}$, et al. Long-term physical training and left ventricular remodeling after anterior myocardial infarction: Results of the Exercise in Anterior Myocardial Infarction (EAMI) trial (EAMI Study Group). J Am Coll Cardiol 1993; 22: 1821-1829.

6. Jugdutt BI, Michorowski BL, Kappagoda CT. Exercise training after anterior Q wave myocardial infarction: Importance of regional left ventricular function and topography. J Am Coll Cardiol 1988; 12: $362-372$.

7. Ornish D, Scherwitz LW, Doody RS, Kesten D, McLanahan SM, Brown SE, et al. Effects of stress management training and dietary changes in treating ischemic heart disease. JAMA 1983; 249: 54-59.

8. Koizumi T, Miyazaki A, Komiyama N, Sun K, Nakasato T, Masuda $\mathrm{Y}$, et al. Improvement of left ventricular dysfunction during exercise by walking in patients with successful percutaneous coronary intervention for acute myocardial infarction. Circ J 2003; 67: 233-237.

9. Chiba M, Nakamura M, Kanaya Y, Kobayashi N, Ueshima K, Kawazoe K, et al. Improvement in lower limb vasodilatory reserve and exercise capacity in patients with chronic heart failure due to valvular heart disease. Eur Heart J 1997; 18: 1931-1936.

10. Tei C. New non-invasive index for combined systolic and diastolic ventricular function. J Cardiol 1995; 26: 135-136.

11. Otsuka Y, Takaki H, Okano Y, Satoh T, Aihara N, Matsumoto T, et al. Exercise training without ventricular remodeling in patients with moderate to severe left ventricular dysfunction early after acute myocardial infarction. Int J Cardiol 2003; 87: 237-244.

12. Eto Y, Koike A, Matsumoto A, Momomura S, Tajima A, Aizawa T, et al. Early aerobic training increases end-tidal $\mathrm{CO}_{2}$ pressure during exercise in patients after acute myocardial infarction. Circ J 2004; 68: $778-783$.

13. Tei C, Ling LH, Hodge DO, Bailey KR, Oh JK, Rodeheffer RJ, et al. New index of combined systolic and diastolic myocardial performance: A simple and reproducible measure of cardiac function: A study in normals and dilated cardiomyopathy. J Cardiol 1995; 26: $357-366$.

14. Tei C, Dujardin KS, Hodge DO, Kyle RA, Tajik AJ, Seward JB. Doppler index combining systolic and diastolic myocardial performance: Clinical value in cardiac amyloidosis. $J$ Am Coll Cardiol 1996; 28: 658-664.

15. Tei C, Dujardin KS, Hodge DO, Bailey KR, McGoon MD, Tajik AJ, et al. Doppler echocardiographic index for assessment of global right ventricular function. J Am Soc Echocardiogr 1996; 9: 838-847.

16. Tei C, Nishimura RA, Seward JB, Tajik AJ. Noninvasive Dopplerderived myocardial performance index: Correlation with simultaneous measurements of cardiac catheterization measurements. $J$ Am Soc Echocardiogr 1997; 10: 169-178.

17. Levy WC, Cerqueira MD, Abrass IB, Schwartz RS, Stratton JR. Endurance exercise training augments diastolic filling at rest and during exercise in healthy young and older men. Circulation 1993; 88: $116-126$.

18. Takemoto KA, Bernstein L, Lopez JF, Marshak D, Rahimtoola SH, Chandraratna PA. Abnormalities of diastolic filling of the left ventricle associated with aging are less pronounced in exercise-trained individuals. Am Heart J 1992; 124: 143-148.

19. Nixon JV, Wright AR, Porter TR, Roy V, Arrowood JA. Effects of exercise on left ventricular diastolic performance in trained athletes. Am J Cardiol 1991; 68: 945-949. 